\title{
Prospective study of patients aged 55 years or less with acute myocardial infarction between 1981 and 1985: outcome 7 years and beyond
}

Jane S Skinner, Catherine J Albers, John Goudevenos, Carolyn Fraser, Olusola Odemuyiwa, Roger J C Hall, Philip C Adams

\begin{abstract}
Objective-To determine the long-term prognosis of patients after a myocardial infarction (MI) at a young age.

Design-Prospective cohort study of patients aged 55 years or less suffering a myocardial infarction.

Setting-A single coronary care unit admitting patients from the community.

Patients-255 consecutive patients (210 men) aged 55 years or less admitted between 1981 and 1985 after acute MI. Twenty four patients died in hospital or within 3 months of infarction and 11 were lost to further follow up after discharge. Of the remaining patients, 150 (mean (SD) age $48(5 \cdot 7)$ years) able to exercise 3 weeks after infarction and who agreed to undergo coronary angiography were recruited to a study group and seen 18 months, and 3, 5, and 7 years after MI. In addition, a cross sectional analysis of survival was made to a median of 120 months. Seventy 3 month survivors (mean (SD) age $48(5 \cdot 8)$ years) were not recruited to the study group but were traced for late survival through their general practitioners and family health service associations to a median of 130 months.
\end{abstract}

Main outcome measures-Survival in young patients after $M I$ and the survival of 3 month survivors stratified by their ability to exercise and agreement to undergo angiography. The rate of coronary artery surgery (CAGB) and reinfarction during the first 7 years after index MI in patients recruited to the study group.

Results-Sixteen patients (6\%) died in hospital and eight $(3 \%)$ within 3 months of the index infarction. The 7 and 11 year survival rates in the whole cohort of 255 patients were $80 \%$ and $66 \%$ respectively using life table methods. Survival 7 years after MI, in patients recruited to the study group was better than in those not recruited $(93 \% v 79 \%, P=0.001)$, but thereafter mortality in the study group accelerated and there was no significant difference in survival 11 years after infarction $(76 \% v 67 \%, P=0.05)$. There was a trend towards higher mortality in patients with multivessel disease and severely impaired left ventricular function. During the first 7 years after MI, 38 of 150 patients in the study group under- went CABG and 19 suffered reinfarction, which was fatal in three.

Conclusion-The medium-term prognosis of young survivors of MI is good, particularly in patients recruited to the study group. After 7 years there is an increase in mortality and the long-term prognosis is less favourable. This should be taken into account when planning future management and follow up of young patients after MI.

(Br Heart f 1995;74:604-610)

Keywords: acute myocardial infarction, prognosis after infarction in young patients, survival after infarction in young patients

Patients are naturally anxious about their prognosis after recovery from an acute myocardial infarction. Age along is an independent indicator of good prognosis in hospital and at 1 year after infarction. ${ }^{12}$ Younger patients also tend to have less extensive coronary artery disease and better left ventricular function with 3 year survival rates for patients aged 60 years or less after infarction of 93-95\%. ${ }^{34}$ The long-term prognosis of young patients after infarction is less well studied, however, and longer term follow up studies are essential to provide this information. We report the survival data from a cohort of 255 patients aged 55 years or less admitted to a single coronary care unit between 1981 and 1985.

\section{Patients and methods}

From October 1981 to March 1985, 255 patients aged 55 years or less, were admitted to the coronary care unit of the Royal Victoria Infirmary with a confirmed diagnosis of acute myocardial infarction. Acute infarction was defined if at least two of three of the following criteria were present: (1) a history of typical ischaemic sounding chest pain lasting for more than 30 min; (2) serial electrocardiogram (ECG) changes compatible with acute infarction; and (3) a rise in creatinine kinase to twice the upper limit of normal for our laboratory. All patients were considered for enrolment into a long-term prospective study. Only patients able to exercise 3 weeks after infarction and who agreed to undergo coronary angiography were recruited; 150 patients were enrolled (table 1). Of the 255 patients admitted, 16 died in hospital and six within 3 weeks 
Table 1 Patients admitted to a single coronary care unit with acute infarction between October 1981 and March 1985

\begin{tabular}{lc}
\hline No of patients admitted with acute infarction & 255 \\
Inhospital deaths & 16 \\
Early out of hospital deaths (<3 months) & $8^{\star}$ \\
No of patients enrolled in the study group & 13 \\
Cardiac contraindications to exercise & 24 \\
Non-cardiac contraindications to exercise & 14 \\
Patients refused & 30 \\
Administrative reasons & 81 \\
Total no of patients no enrolled & 150 \\
No of patients enrolled in the study group & \\
ॠNone performed exercise tests or underwent coronary \\
angiography. Six died within 3 weeks of infarction and two \\
were excluded for administrative reasons.
\end{tabular}

of discharge. Two further patients who died within 3 months of discharge had not performed exercise tests or undergone angiography due to administrative reasons and were also excluded. Thirteen patients were excluded because of cardiac reasons: two had undergone previous coronary artery surgery, two required emergency coronary artery surgery, one suffered from severe aortic stenosis, seven from grade 4 heart failure, and one had recently undergone coronary angiography. Twenty four patients were excluded because of non-cardiac disease: psychiatric illness (five), peripheral emboli (two), malignancy (two), chronic renal failure (one), diabetes melitus with complications (one), rheumatoid arthritis (one), respiratory disease (one), severe peripheral vascular disease (two), orthopaedic problems (five), and neurological illnesses (four). Fourteen patients refused to participate in the study and $30(12 \%)$ were excluded for administrative reasons.

\section{PATIENTS NOT RECRUITED INTO THE STUDY} GROUP

Eleven of the 81 hospital survivors not recruited to the study group were lost to further follow up after discharge from hospital. The remaining 70 patients alive 3 months after infarction were traced via their general practitioners and family health service associations. Their survival status was recorded to a median of 130 months after the index infarction. Minimum follow up was 89 months.

\section{PATIENTS RECRUITED TO THE STUDY GROUP Coronary angiography}

Coronary and left ventricular angiography were performed using Judkins' technique a mean (range) of 3 (1-6) months after infarction. Each angiogram was reviewed by two independent observers and any differences of opinion resolved by a consensus agreement. Each of the main arteries was viewed in at least two orthogonal planes, stenoses of at least $70 \%$ reduction in intraluminal diameter were recorded, and each angiogram classified as showing one, two, or three vessel disease. Ejection fractions were calculated from the $30^{\circ}$ right anterior oblique angiogram by the arealength method for single plane angiograms. ${ }^{5}$ The quality of the left ventriculogram was too poor for analysis in four patients. Patients were referred for coronary artery surgery if they suffered restricting angina despite maxi- mum medical treatment. One patient with a stenosis $(>70 \%)$ of the left main stem also underwent surgery, but no other patients were referred only on angiographic evidence.

\section{FOLLOW UP}

Patients were seen 18 months, and 3, 5, and 7 years post-infarction. ${ }^{67}$ Patients who were not able to attend were asked to complete postal questionnaires or local hospital notes were reviewed. If patients had moved away from the area and were under the care of other hospitals, their current consultant was contacted for information. Seven years after infarction, 130 patients (94\% of those alive) were seen, four completed questionnaires at home, and hospital notes were reviewed for five. Death, nonfatal myocardial infarction, and need for coronary artery surgery were recorded. In addition, a cross sectional analysis of survival was made to a median of 120 months. The minimum follow up was 90 months. No patients have been lost to follow up. Patients were not withdrawn from analysis after nonfatal infarction or coronary artery surgery. Information on cause of death was obtained from hospital records, postmortem reports, and death certificates. One patient required cardiac transplantation for severe heart failure. It was thought unlikely that this patient would survive for very long without transplantation and a "death" was recorded at the time of transplantation.

\section{STATISTICAL ANALYSIS}

Categorical variables were compared using a $\chi^{2}$ statistic. Life table methods were used for survival analyses and the log rank test and log rank test for trend used to estimate differences between groups.

\section{Results}

Twenty four patients died in hospital or within 3 months of discharge from hospital. Eleven patients were lost from further follow up immediately after discharge. Hence, the basis of the study of mortality in the whole cohort was 255 and patients lost to follow up after discharge were censored at that time. Some 220 patients were alive at 3 months and form the basis of the study of 3 month survivors stratified by exercise and angiography.

\section{CLINICAL CHARACTERISTICS}

Whole cohort $(n=255)$

Some 210 patients (82\%) were men and 45 (18\%) women. Mean (SD) (range) age was 48 $(5 \cdot 7)(26-55)$ years.

Patients not recruited into the study group $(n=70)$ Fifty $(71 \%)$ of the 70 patients alive 3 months after infarction and not enrolled into the study group were men and $20(29 \%)$ women. Mean (SD) (range) age of the 70 patients was 48 $(5 \cdot 8)(31-55)$ years.

\section{Study group $(n=150)$}

Some 130 patients (87\%) were men and 20 (13\%) women. The mean (SD) (range) age of 


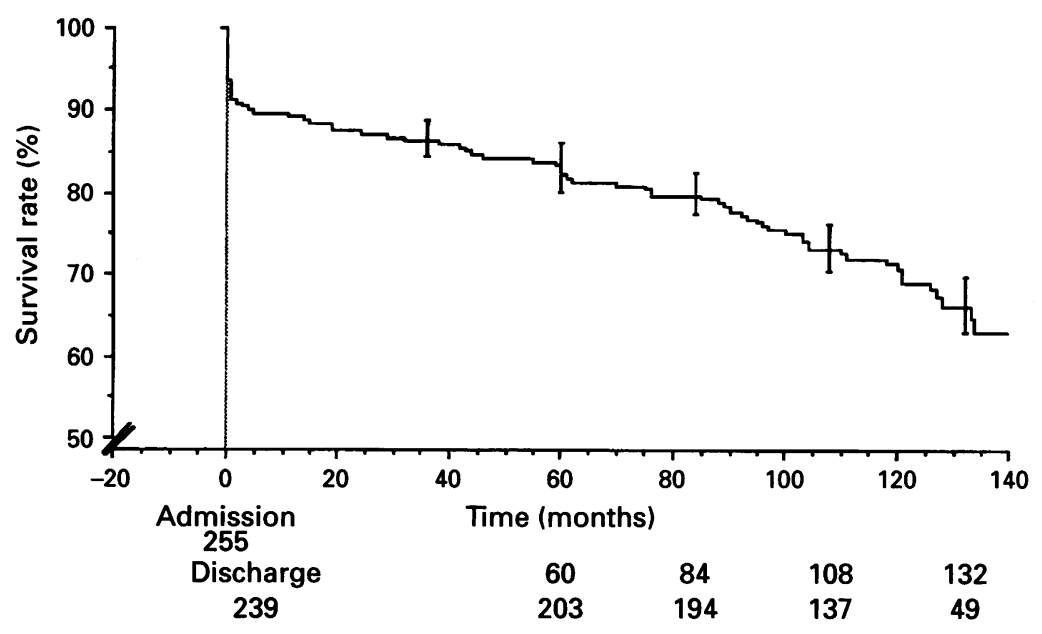

Figure 1 Cumulative life table survival (+ one SE of the percentage survival rate) of all patients admitted with acute infarction. Patients at risk on admission to and discharge from hospital and at 60,84,108, and 132 months are indicated.

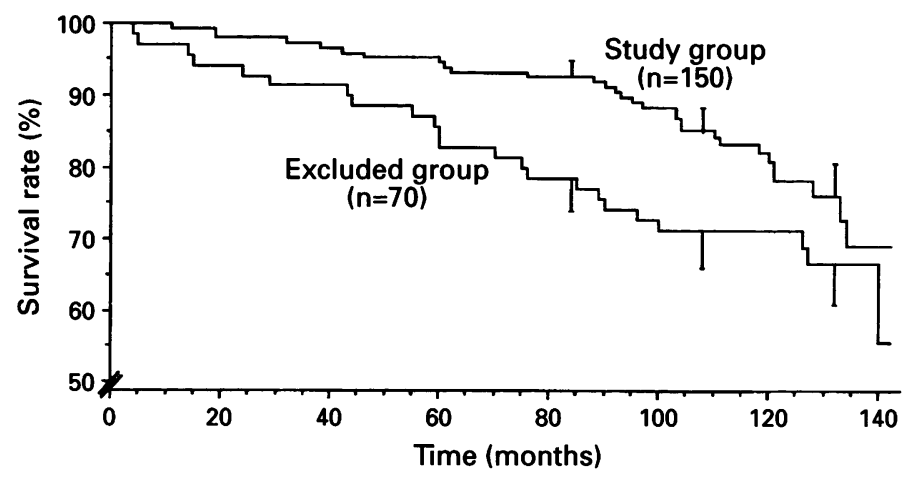

$\begin{array}{lcccc}\text { Months } & 60 & 84 & 108 & 132 \\ \text { No at risk } & & & & \\ \quad \text { Study group } & 143 & 139 & 93 & 26 \\ \text { Excluded group } & 60 & 55 & 44 & 23 \\ P & & 0.001 & 0.007 & 0.05\end{array}$

Figure 2 Cumulative life table survival (+ one SE of the percentage survival rate) of patients with respect to recruitment to the study group. Patients at risk at 60,84, 108, and 132 months are indicated. Difference between groups is tested using the log rank test.

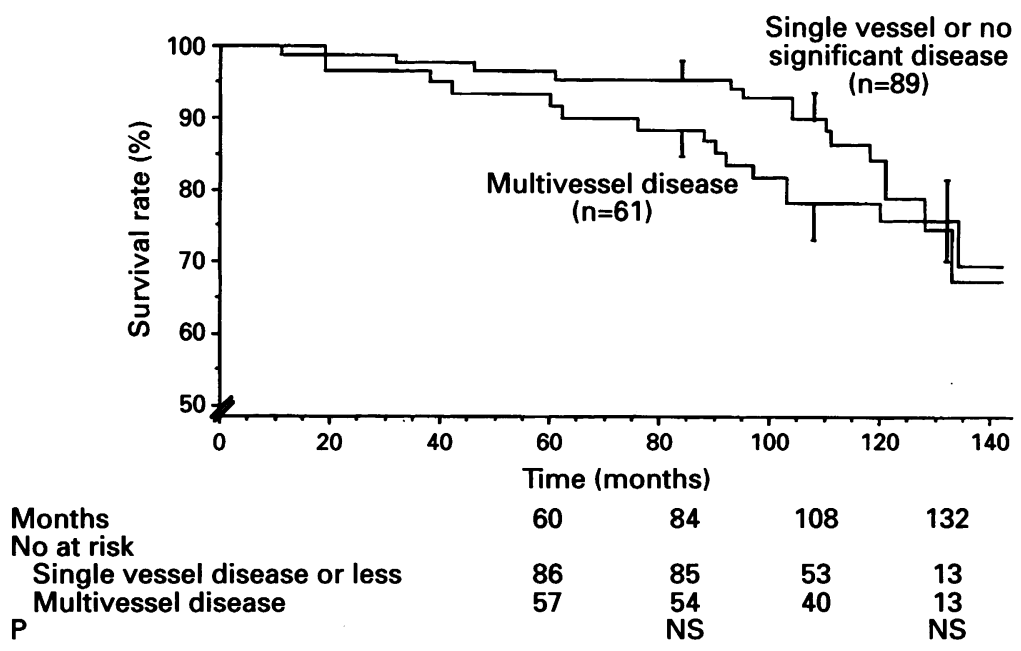

Figure 3 Cumulative life table survival (+ one SE of the percentage survival rate) of the study group with single vessel disease or no significant disease, and multivessel disease. Patients at risk at 60,84,108, and 132 months are indicated. Difference between groups is tested using the log rank test. NS, not significant. the cohort was $48(5 \cdot 74)(26-55)$ years. Seven patients $(5 \%)$ had a history of previous infarction. Standard 12 lead ECGs recorded at the time of admission showed anterior infarction in 60 patients $(40 \%)$ and inferior infarction in 82 $(55 \%)$. In eight patients the infarction could not be classified as either. $Q$ waves evolved in $111(74 \%)$. Only nine patients $(6 \%)$ received streptokinase.

\section{TOTAL MORTALITY}

Whole cohort

Two hundred and fifty five patients were admitted during the recruitment period. Sixteen (6\%) died in hospital and eight within 3 months of infarction. The survival outcome thereafter of 220 patients (95\%) is known of whom 53 (includes one transplantation) have died. Hence, the overall survival status of 244 patients $(96 \%)$ is known. Figure 1 shows survival in the entire cohort. Patients discharged alive but who could not be traced thereafter were censored at discharge.

\section{MORTALITY IN 3 MONTH SURVIVORS}

Patients not recruited into the study group

From 3 months after infarction, 23 (33\%) of the 70 excluded patients traced during the median follow up period of 130 months died. Figure 2 shows survival in these 70 patients not recruited to the study group. The survival in the 150 patients in the study group is shown for comparison.

\section{Study group}

Thirty (20\%) (includes one transplantation) of the 150 patients in the study group died during the median follow up period of 120 months (fig 2). Ten died suddenly, nine after a further acute infarction, one as a complication of emergency first time coronary artery surgery, one as a complication of redo coronary artery surgery, six with severe congestive cardiac failure, and three of non-cardiac causes.

Of the 30 patients in the study group who died, nine patients had coronary artery surgery on one occasion and one had two coronary artery bypass operations. Nine patients had surgery within 7 years of infarction.

Relation between angiographic data and mortality Eighty nine patients $(59 \%)$ in the study group had single vessel coronary artery disease or no significant disease, and $61(41 \%)$ two or three vessel coronary artery disease. There was no significant difference in survival between the respective groups (fig 3 ).

The ejection fraction calculated from the left ventriculogram in 146 patients was equal to or greater than $50 \%$ in $81(56 \%), 30-49 \%$ in 50 (34\%), and less than $30 \%$ in $15(10 \%)$. Reduction in ejection fraction after infarction was associated with higher mortality, particularly when the ejection fraction was less than $30 \%$. The difference between the three groups was significant 7 years after infarction $(0.01<$ $P<0.02$ ) although this was no longer so 9 years after infarction (fig 4). Four patients had an ejection fraction of less than $20 \%$; two have died and one has undergone transplantation. 


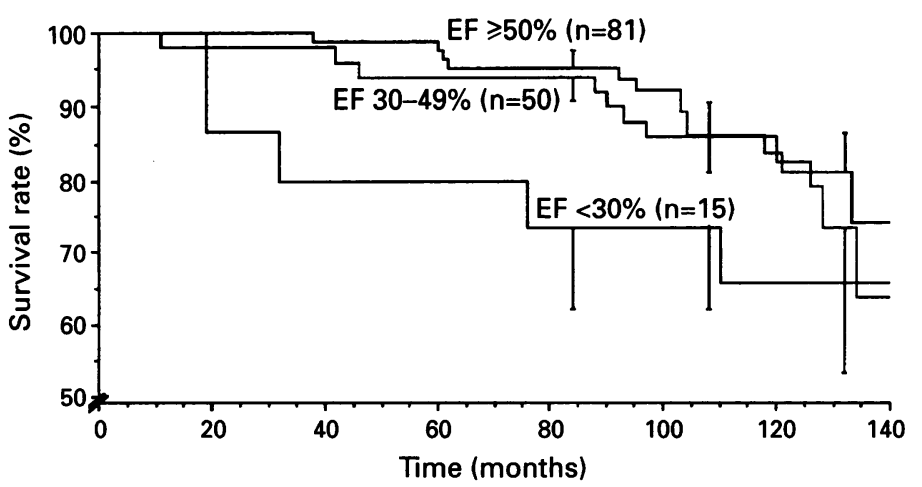

$\begin{array}{lcccc}\text { Months } & 60 & 84 & 108 & 132 \\ \text { No at risk } & & & & \\ \text { EF } \geqslant 50 & 80 & 77 & 48 & 13 \\ \text { EF } 30-49 & 47 & 47 & 32 & 10 \\ \text { EF }<30 & 12 & 12 & 10 & 3 \\ P & & 0.01<P<0.02 & \text { NS } & \text { NS }\end{array}$

Figure 4 Cumulative life table survival (+ one SE of the percentage survival rate) of the study group with normal left ventricular function (ejection fraction $50 \%$ or more) and impaired left ventricular function (ejection fraction 30-49\% and less than 30\%). Patients at risk at $60,84,108$, and 132 months are indicated. Difference between groups is tested using the log rank test for trend. EF, ejection fraction; NS, not significant.

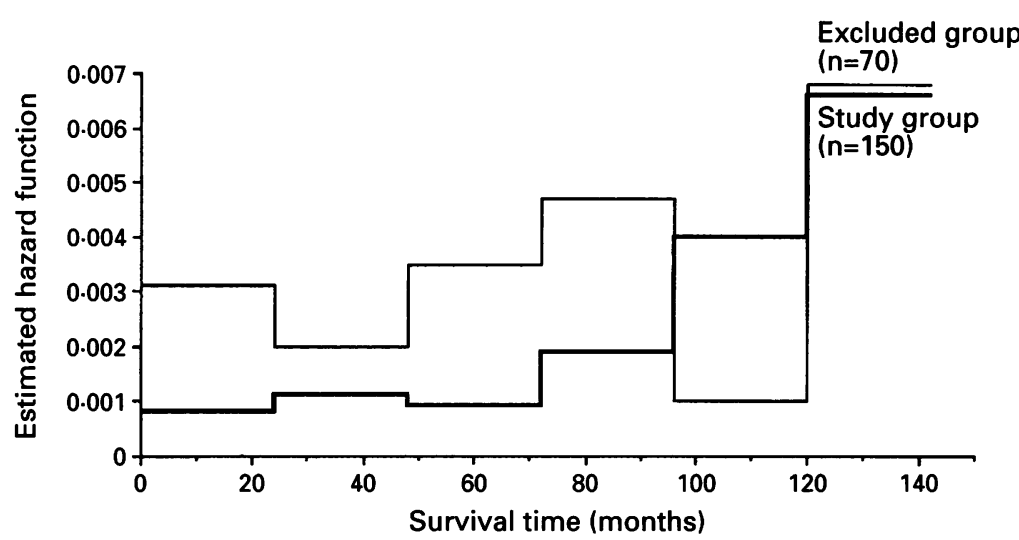

Figure 5 Life table estimate of the hazard function of patients with respect to recruitment to the study group illustrating the risk of patients dying in the two separate groups during different time intervals. The risk of patients dying in the study group remains roughly constant during the first 7 years after which it appears to increase. By contrast, the mortality risk of patients excluded from the study is higher with no distinct change with time.

Comparison of mortality in patients recruited and those not recruited to the study group

Table 2 shows the cumulative life table survival of the total cohort (including inhospital and early out of hospital deaths) and that of 3 month survivors in the study group and excluded group at 7,9 , and 11 years. The differences in survival between the study group and non-study group are significant at 7 years $(P=0.001)$ but not at 11 years $(P=0.05)$.

Table 2 Cumulative life table survival (\%) of the complete cohort (including deaths in hospital and within 3 months of infarction), and patients recruited to, or excluded from, the study group

\begin{tabular}{llll}
\hline & \multicolumn{3}{l}{ Survival (\%) } \\
\cline { 2 - 4 } & Complete cohort & Study group & Excluded group \\
\hline 7 years & $80(194)$ & $93(139)^{\star}$ & $79(55)$ \\
9 years & $73(137)$ & $85(93) \dagger$ & $71(44)$ \\
11 years & $66(49)$ & $76(26) \ddagger$ & $67(23)$ \\
\hline
\end{tabular}

Values in parentheses are number of patients at risk.

${ }^{\star} \mathrm{P}=0.001 ;+\mathrm{P}=0.007 ; \ddagger \mathrm{P}=0.05$ comparing 3 month survivors recruited to the study group with those excluded (log rank test).
Figure 5 is a plot of estimated hazard function of the two groups. The general pattern for risk of dying in patients in the study group remains roughly constant during the first 7 years after which it appears to increase. By contrast, the mortality risk of patients excluded from the study group is higher with no distinct trend.

Outcome 7 years after infarction of the study group Seven years after infarction, $10(7 \%)$ of the 150 patients recruited into the study group had died, nine from cardiac cause. One patient underwent cardiac transplantation 32 months after infarction. Sixteen (11\%) suffered a further non-fatal myocardial infarction. Some patients $38(25 \%)$ underwent coronary artery surgery; 24 of these 38 operations being performed within 18 months of infarction (table 3). Patients with multivessel disease (two or three vessel disease) were more likely than those with single vessel or no disease to have undergone coronary artery surgery, $(P<0.01)$ (table 4). Patients with a poor ejection fraction (30-49\% and less than $30 \%$ ) compare with those with a good ejection fraction $(\geqslant 50 \%)$ were more likely to have undergone coronary artery surgery at 18 months after infarction $(P<0.05)$ but not at 7 years (table 4$)$ (the ejection fraction could not be reliably calculated in one patient who underwent coronary artery surgery by 7 years). Forty four (32\%) patients alive 7 years after infarction were taking $\beta$ blockers, $62(45 \%)$ were taking aspirin, and four $(3 \%)$ were taking angiotensin converting enzyme (ACE) inhibitors.

\section{Discussion}

There are two main findings from this study of survival in young patients after a myocardial infarction. First, the overall, medium-term prognosis of young survivors of infarction is good, but that of 3 month survivors able to exercise 3 weeks after infarction is significantly better than patients unable to perform an exercise test. Second, mortality in young patients able to exercise after acute infarction tends to accelerate after 7 years such that the difference in survival between patients who can and cannot exercise may not persist as the follow up period is extended.

Table 3 Events suffered by 150 patients in the study group during the first 7 years after myocardial infarction

\begin{tabular}{lc}
\hline Event & No of patients \\
\hline Cardiac death only & $6(4 \cdot 00)$ \\
Non-cardiac death & $1(0 \cdot 67)$ \\
Cardiac transplantation & $1(0 \cdot 67)$ \\
Non fatal MI only & $9(6 \cdot 00)$ \\
Non-fatal Mi and later death & $1(0 \cdot 67)$ \\
Early CABG only & $19(12 \cdot 67)$ \\
Late CABG only & $10(6 \cdot 67)$ \\
Early CABG and non-fatal MI & $2(1 \cdot 33)$ \\
Late CABG and non-fatal MI & $4(2 \cdot 67)$ \\
Early CABG and later death & $2(1 \cdot 33)$ \\
Late CABG and late redo CABG & $1(0 \cdot 67)$ \\
No event & $94(62 \cdot 67)$ \\
\hline
\end{tabular}

Values in parentheses are percentages.

Early CABG, coronary artery bypass grafting within 18 grafting between 18 months and 7 years after infarction; MI, myocardial infarction. 
Table 4 Extent of coronary artery disease and referral for coronary artery surgery

\begin{tabular}{|c|c|c|c|c|c|}
\hline & \multicolumn{5}{|c|}{ No of patients } \\
\hline & $\begin{array}{l}\text { SVD or } \\
\text { no disease } \\
(n=89)\end{array}$ & $\begin{array}{l}M V D \\
(n=61)\end{array}$ & $\begin{array}{l}E F \geqslant 50 \% \\
(n=81)\end{array}$ & $\begin{array}{l}E F 30-49 \% \\
(n=50)\end{array}$ & $\begin{array}{l}E F<30 \% \\
(n=15)\end{array}$ \\
\hline $\begin{array}{l}\text { CABG within } 18 \text { months } \\
\text { CABG within } 7 \text { years }\end{array}$ & $\begin{array}{c}7(7 \cdot 9) \dagger \\
13(14 \cdot 6) \dagger\end{array}$ & $\begin{array}{l}17(27 \cdot 9) \\
25(40 \cdot 9)\end{array}$ & $\begin{array}{r}9(11 \cdot 1) \\
18(22 \cdot 2)\end{array}$ & $\begin{array}{r}9(18) \\
13(26)\end{array}$ & $\begin{array}{l}6(40)^{\star} \\
6(40)\end{array}$ \\
\hline
\end{tabular}

Values in parentheses are percentages.

CABG, coronary artery bypass graft; SVD, single vessle disease; MVD, multivessel disease; EF, ejection fraction.

$\chi^{2}$ statistic to compare the respective groups.

$\chi^{2}$ statistic to compare
$\star \mathrm{P}<0.05 ;+\mathrm{P}<0.01$

A recognised problem in all studies of survival is the decrease in the number of patients available with increasing duration of follow up. In this study 194 patients were available for calculation 7 years after infarction, although this decreased to 49 by 11 years. There are few studies of large cohorts, however, particularly when the population of interest is restricted to a younger age group and the follow up period is longer. There are no large cohort studies restricted to patients aged less than 56 years at the time of infarction.

The heterogeneity of published studies of survival after infarction confounds comparison. Patients may be restricted to particular age groups, ${ }^{38}$ studies that report angiographic data often do not include patients with other serious illnesses and severe heart failure ${ }^{4}$ and even before the use of thrombolysis there was a decrease in the 3 year mortality of 28 day survivors of myocardial infarction between 1966 and 1967 and between 1981 and $1982 . .^{10} \mathrm{We}$ report survival in our cohort as a whole with follow up data in $96 \%$ of all patients. We also report survival in 3 month survivors stratified by ability to exercise and agreement to angiography. We elected to consider the patient undergoing cardiac transplantation as having "died" (without transplantation she would almost certainly have died and we therefore feel this is justified, although the time of her "death" which we used may have been a little premature).

Table 5 summarises survival in patients after acute myocardial infarction in published series. The inhospital mortality of our patients is comparable with that reported elsewhere of all patients under the age of 70 years. ${ }^{11}$ Survival in our patients, including those who died in hospital or soon after discharge, seems at least as good and possibly better than in published series with one exception ${ }^{13}$ (table 5). We have not yet reached 15 years of follow up, however, and as there is a clear trend towards an acceleration in mortality after 7 years the mortality of our cohort may approach that of others. Roth $e t$ $a l^{13}$ report much lower mortality which seems in sharp contrast to our own findings and those of others. In the study of Roth et al, however, the survival status of only 10 patients beyond 10 years is reported and the confidence intervals, although not shown, must be wide.

Fioretti et $a l^{14}$ demonstrated a pronounced difference in mortality 1 year after infarction between patients of all ages who could exercise $(7 \%)$ and those who could not do so for cardiac reasons $(56 \%)$. As cardiac disability was not the only indication for exclusion from our study group, the absolute mortality in patients not enrolled in the study group and the difference between the groups are less noticeable.

Norris et $\mathrm{al}^{9}$ also found a significant difference in mortality after infarction between patients stratified by agreement to angiography and ability to exercise 4 weeks after infarction (13\% v 33\% during a mean follow up of 3.5 years). Although we too found that mortality in patients recruited to angiography and exercise testing is lower than those excluded, mortality in our patients in both groups is lower than reported by Norris et al. Our patients are a little younger-that is, less than 56 years compared with less than 60 years, and angiographically

Table 5 Survival of patients with acute myocardial infarction from published series (with dates of recruitment) before routine thrombolysis. The number of patients studied and any exclusion/inclusion criteria are shown. The number of patients available for calculation of \% survival is indicated where this data could be extracted from the paper. The survival of patients in the current study is also shown

\begin{tabular}{|c|c|c|c|c|}
\hline Reference & Population & Exclusions/inclusion criteria & $\begin{array}{l}\text { Survival time } \\
\text { (years) }\end{array}$ & $\begin{array}{l}\text { Survival } \\
(\%)\end{array}$ \\
\hline $\begin{array}{l}\text { Hoit et al }{ }^{11} \\
\qquad(1968-1983)\end{array}$ & $\mathrm{n}=1874$, aged $<70$ & No exclusions & Inhospital & 94 \\
\hline $\begin{array}{l}\text { Merrilees et al }{ }^{\prime 2} \\
\quad(1966-1967)\end{array}$ & $\begin{array}{l}\mathrm{n}=88, \text { aged }<50 \\
\mathrm{n}=169, \text { aged } 50-59\end{array}$ & $\begin{array}{l}\text { Inpatient deaths excluded } \\
\text { Inpatient deaths excluded }\end{array}$ & $\begin{array}{r}9 \\
15 \\
9 \\
15\end{array}$ & $\begin{array}{l}75 \\
50(n=43) \\
45 \\
30(n=49)\end{array}$ \\
\hline $\begin{array}{r}\text { Robinson et al } \\
(1965-1982)\end{array}$ & $\mathrm{n}=684$, aged $<60$ & $\begin{array}{l}\text { All deaths within } 28 \text { days excluded } \\
1965-1975 \text { women excluded } \\
\text { (1978-1982 women included) }\end{array}$ & 15 & $39(n=60)$ \\
\hline $\begin{array}{l}\text { Roth et al }{ }^{13} \\
\quad \text { (Before 1967) }\end{array}$ & $n=53$, aged $<40$ & None stated & 16 & $77(n=10)$ \\
\hline $\begin{array}{l}\text { Norris et al } 9 \\
\quad(1977-1982)\end{array}$ & $\begin{array}{l}\text { Study group } \\
\mathrm{n}=325 \text {, aged }<60\end{array}$ & $\begin{array}{l}\text { Women excluded } \\
\text { Coronary angiography and exercise } \\
\text { tests performed } 4 \text { weeks post-MI }\end{array}$ & Mean 3.5 & 87 \\
\hline & $\begin{array}{l}\text { Non-study group } \\
\mathrm{n}=70 \text {, aged }<60\end{array}$ & No coronary angiography/exercise test & Mean 3.5 & 67 \\
\hline $\begin{array}{l}\text { Roubin et al }{ }^{4} \\
\quad(1976-1981)\end{array}$ & $\mathrm{n}=229$, aged $<60$ & $\begin{array}{l}\text { Patients with severe heart failure, other life } \\
\text { threatening illness and/or previous CABG excluded } \\
\text { Coronary angiography performed } 2 \text { weeks post-MI }\end{array}$ & $\begin{array}{l}1 \\
2 \\
3\end{array}$ & $\begin{array}{l}96(n=168) \\
96 \\
96(n=83)\end{array}$ \\
\hline $\begin{array}{l}\text { Fiorett et al }{ }^{14} \\
\quad(1981-1983)\end{array}$ & & $\begin{array}{l}\text { Inpatient cardiac intervention and deaths excluded } \\
\text { Exercise test before discharge }\end{array}$ & 1 & \\
\hline $\begin{array}{l}\text { Current study } \\
(1981-1985)\end{array}$ & $\begin{array}{l}n=43 \\
n=62 \\
n=255, \text { aged } \geqslant 55\end{array}$ & $\begin{array}{l}\text { No exercise (cardiac limitations) } \\
\text { No exercise (non cardiac limitation) } \\
\text { None }\end{array}$ & $\begin{array}{l}\text { Inhospital } \\
9 \\
11\end{array}$ & $\begin{array}{l}44 \\
92 \\
94 \\
73(n=137) \\
66(n=49)\end{array}$ \\
\hline
\end{tabular}

MI, myocardial infarction; CABG, coronary artery bypass graft surgery. 
may have had less severe disease. The survival to 3 years of the patients enrolled into the study group was $97 \%$ and is more in agreement with that found by Roubin et al ${ }^{14}$ who found a survival rate of $96 \%$ to 3 years (table 5). By contrast, the prevalence of multivessel disease is slightly higher in our study, (41\%) than in the study by Roubin et al (36\%).

We have found that 7 years after infarction the survival of patients in the study group remains good and the difference from those excluded reaches significance. Beyond this, however, the risk of dying in patients in the study group increases. The pattern of risk for patients in the excluded group is less clear as the decline between 8 and 10 years must be interpreted with caution as there were few deaths during this time interval. The apparent absence of any significant difference in survival between the two groups 11 years after infarction must be considered with the reduction in the number of patients in mind. However, patients who are not recruited to investigation more often have other serious illnesses. Patients with severe symptomatic heart failure are often unable to exercise and are therefore excluded, although their prognosis is poor. Consequently, patients who are not recruited may die earlier, although the total mortality may not differ between the two groups if follow up is sufficiently long.

After 7 years, only $13 \%$ of our patients suffered a recurrent infarction, $16 \%$ of which were fatal. Other studies (table 6) have tended to report a higher rate of reinfarction, although studies of a similar duration and restricted to patients of a similar age to ours are lacking. Although our rate of recurrent infarction is probably lower than in other studies, the reinfarction rate applies only to patients recruited to the study group and only up to 7 years after infarction. We have already shown that the prognosis of patients excluded from the study group is worse than those recruited and this may apply, not only to survival, but also to recurrent infarction. Similarly, as the mortality of recruited patients tends to accelerate after 7 years, so may the rate of reinfarction.

The ejection fraction ${ }^{39}$ and number of diseased vessels ${ }^{3}$ after infarction in patients aged 60 years or less are independent predictors of survival. Age is also an independent predictor of prognosis after infarction, although younger patients also tend to have less extensive coronary artery disease and better preserved left ventricular function. However, our young patients had a relatively high rate of coronary artery surgery, namely, 38 of the 150 patients in the study group having been operated on

Table 6 Recurrent myocardial infarction (MI) in patients with acute myocardial infarction from published series (with dates of recruitment)

\begin{tabular}{|c|c|c|c|}
\hline Reference & $\begin{array}{l}\text { Age } \\
\text { (years) }\end{array}$ & $\begin{array}{l}\text { Time of follow up } \\
\text { after MI }\end{array}$ & $\begin{array}{l}\text { Reinfarction } \\
\text { rate }(\%)\end{array}$ \\
\hline $\begin{array}{l}\text { Stone et al }{ }^{15} \\
\text { Framingham }(1950-1970)^{16}\end{array}$ & $<76$ & Mean 30.8 mths & 15 \\
\hline $\begin{array}{l}\text { Male } \\
\text { Female } \\
\text { Norris et al (1977-1982) } \\
\text { Current study }\end{array}$ & $\begin{array}{l}<80 \\
<80 \\
<60 \\
\leqslant 55\end{array}$ & $\begin{array}{l}5 \text { years } \\
5 \text { years } \\
\text { Mean } 3 \cdot 5 \text { years } \\
7 \text { years }\end{array}$ & $\begin{array}{l}13 \\
39 \\
12(20 \% \text { fatal }) \\
13(16 \% \text { fatal })\end{array}$ \\
\hline
\end{tabular}

within the first 7 years, 24 of whom within the first 18 months. The high surgery rate may have mitigated the adverse effects of multivessel disease and impaired left ventricular function on survival during early and medium-term follow up. ${ }^{17} 18$ This effect may not persist with longer periods of follow up as the prognostic gain from coronary artery surgery performed nearly 10 years earlier is lessened. At the time that many of our patients underwent coronary artery surgery, an internal mammary conduit, which is associated with a better prognosis than a vein graft when grafted to the left anterior descending artery, ${ }^{19}$ was not routinely used and its use in our patients might have extended the survival benefit obtained from coronary artery surgery. However, we repeated the survival analysis with patients having surgery excluded at the time of operation and found that the increased mortality risk after 7 years still persisted. We do not have data for drug treatment or rate of coronary artery surgery in the nonstudy group. With the exception of one patient with severe left main stem disease, patients in the study group were not operated on unless they suffered from restricting angina despite medical treatment. The fact that these patients were under regular follow up, however, may have led to such patients being more readily identified.

Aspirin ${ }^{20}$ thrombolytic treatment, ${ }^{2021} \beta$ blockers, ${ }^{22}{ }^{23}$ and ACE inhibitors ${ }^{24}{ }^{25}$ improve prognosis after acute infarction. During recruitment of our patients these treatments were not standard practice, but were at the discretion of a single consultant cardiologist responsible for patient care. The importance of prophylactic treatment in patients with established coronary artery disease has become increasingly apparent since our patients first presented. ${ }^{26-28}$ Survival of the study group up to 7 years after infarction is excellent and prophylactic treatment would not have made a significant impact. However, thrombolytic agents given soon after infarction and aspirin might have favourably influenced mortality in patients who died either in hospital or soon after discharge. These and other strategies might also have been beneficial in patients not recruited to the study group and in the long-term prognosis beyond 7 years of the whole group. Chronic aspirin treatment has also been shown to have significant benefit in patients with a past history of myocardial infarction. ${ }^{26}$ Seven years after infarction less than half the study group were taking aspirin. ACE inhibitors have a favourable effect on the prognosis of patients with impaired left ventricular function. ${ }^{27}$ Seven years after infarction 12 patients in the study group who had severely impaired left ventricular function after infarction were still alive, although overall only four patients in the study group were taking ACE inhibitors. Therapeutic manoeuvres to retard coronary artery disease progression, such as aggressive lipid lowering measures, ${ }^{28}$ early in the natural history of patients with coronary artery disease are also likely to have a favourable impact on later prognosis.

The medium-term survival in young survivors after a myocardial infarction is good but 
mortality increases after 7 years. These findings should be taken into account when planning future management and follow up protocols of young survivors of acute infarction. Moreoever, investigation of patients without prior coronary artery surgery to identify those who have progressed from a low risk to a high risk group and the judicious use of coronary artery surgery in these patients should possibly be considered. Attention to other chronic, prognostic treatment is also required in young patients at all stages after infarction.

This study was supported by a grant from the British Hear Foundation.

1 Rich MW, Bosner MS, Chung MK, Shen J, McKenzie JP. Is age an independent predictor of early and late mortality in patients with acute myocardial infarction $A m \Im$ Med 1988;92:7-13.

2 Martin CA, Thompson PL, Armstrong BK, Hobbs MST, De Klerk N. Long term prognosis after recovery from myocardial infarction: a nine year follow up of the Perth myocardial infarction: a nine year follow up of

3 Sanz G, Castaner A, Betriu A, Magrina J, Roig E, Coll S, et al. Determinants of prognosis in survivors of myocardial infarction. A prospective angiographic study. $N$ Engl $\mathscr{f}$

4 Roubin GS, Harris PJ, Bernstein L, Kelly DT. Coronary artery anatomy and prognosis after myocardial infarction in patients 60 years of age or younger. Circulation 1983 67:743-9.

5 Sandler H, Dodge HT. The use of single plane angiocardiograms for the calculation of left ventricular volume in man. Am Heart $\mathcal{F}$ 1965;75:325-34.

6 Peart I, Odemuyiwa O, Albers C, Hall A, Kelly C, Hall RJC Exercise testing soon after myocardial infarction: its relation to course and outcome at one year in patients aged less than 55 years. Br Heart $₹$ 1989;61:231-7.

7 Odemuyiwa O, Peart I, Albers C, Hall RJC. Exercise tests at 3 weeks, 6 weeks, and 18 months after infarction and the outcome at 3 years in young patients (under 55 years). Eur outcome at 3 years in you

8 Robinson K, Conroy RM, Mulcahy R, Madden B. Relation of infarct site to 15 year prognosis in patients who survived
for 28 days after a first myocardial infarction. Br Heart $\mathcal{f}$ for 28 days afte

9 Norris RM, Barnaby PF, Brandt PWT, Geary GG, Whitlock RML, Wild CJ, et al. Prognosis after recovery from firs acute myocardial infarction: determinants of reinfarction and sudden death. Am $\mathcal{F}$ Cardiol 1984;53:408-13.

10 Stewart AW, Fraser J, Norris RM, Beaglehole R. Changes in severity of myocardial infarction and the three year survival rates after myocardial infarction in Auckland, 1966-7 and 1981-2. BMF 1988;297:517-9.

11 Hoit BD, Gilpin EA, Henning H, Maisel AA, Dittrich H, Carlisle J, et al. Myocardial infarction in young patients: an analysis by age subsets. Circulation 1986;74:712-21.

12 Merrilees MA, Scott PJ, Norris RM. Prognosis after myocardial infarction: results of 15 year follow up. $B M F 1984$; 288:356-9.

13 Roth O, Berki A, Wolff GD. Long range observations in fifty three young patients with myocardial infarction. $A m \mathcal{F}$ Cardiol 1967;19:331-8.

14 Fioretti P, Brower RW, Simoons ML, Bos RJ, Baardman T, Beelen A, et al. Prediction of mortality during the first year fter acute myocardial infarction from clinical variables and stress test at hospital discharge. Am $\mathcal{F}$ Cardiol 1985; 55:1313-8.

15 Stone PH, Raabe DS, Jaffe AS, Gustafson N, Muller JE, Turi ZG, et al for the MIIIS Study Group. Prognostic significance of location and type of myocardial infarction: infependent adverse outcome associated with anterior location. $¥ \mathrm{Am}$ Coll Cardiol 1988;11:453-63.

16 Kannel WB, Sorlie P, McNamara PM. Prognosis after initial infarction: the Framingham study. Am $\mathcal{F}$ Cardiol 1979;44: 53-9.

17 Varnauska E and the European Coronary Surgery Study Group. Twelve year follow up of survival in the randomised European coronary surgery study. Lancet 1988;319:332-7.

18 Alderman EL, Bourassa MG, Cohen LS, Davis KB, Kaiser GG, Killip T, et al (CASS investigators). Ten year follow up of survival and myocardial infarction in the randomised coronary artery surgery study. Circulation 1990;82. $1629-47$.

19 Loop FD, Lytle BW, Cosgrove DM, Stewart RW, Goormastic M, Williams GW, et al. Influence of the internal mammary artery graft on 10 year survival and other cardiac events. N Engl $¥ M e d$ 1986;314:1-6.

20 ISIS 2 (Second International Trial of Infarct Survival) Collaborative Group. Randomised trial of intravenous Collaborative Group. Randomised trial of intravenous
streptokinase, oral aspirin, both, or neither among 17, 187 streptokinase, oral aspirin, both, or neither among 17, 187 cases of suspected

21 Simoons ML, Vos J, Tijssen JGP, Vermeer F, Verheught FWA, Krauss XH, et al. Long term benefit of early thrombolytic therapy in patients with acute myocardial infarction: 5 year follow up of a trial conducted by the Interuniversity Cardiology Institute of the Netherlands. FACC 1989;14:1609-15.

22 ISIS-1 (First International Study of Infarct Survival) Collaborative Group. Randomised trial of intravenous atenolol among 16,027 cases of suspected acute myocardial infarction. ISIS-1. Lancet 1988;ii: 57-66.

23 Norwegian Multicenter Study Group. Timolol induced reduction in mortality and reinfarction in patients surviving acute myocardial infarction. $N$ Engl $f$ Med 1981;304: $801-7$.

24 The acute infarction ramipril efficacy (AIRE) study investigators. Effect of ramipril on mortality and morbidity of gators. Effect of ramipril on mortality and morbidity of survivors of acute myocardial infarction with
dence of heart failure. Lancet 1993;342:821-7.

25 Pfeffer MA, Braunwald E, Moye LA, Basta L, Brown EJ, Cuddy TE, et al on behalf of the SAVE investigators. Effect of captopril on mortality and morbidity in patients with left ventricular dysfunction after acute myocardial infarction. Results of the survival and ventricular enlargement trial. $N$ Engl f Med 1992;327:669-77.

26 Antiplatelet trialists' collaboration. Collaborative overview of randomised trials of antiplatelet therapy-I: prevention of death, myocardial infarction, and stroke by prolonged antiplatelet therapy in various categories of patients. $B M \mathcal{F}$ 1994;308:81-106.

27 The CONSENSUS Trial Study Group. Effects of enalapril on mortality in severe congestive heart failure; the results of the cooperative north Scandinavian enalapril survival study (CONSENSUS). $N$ Engl $₹$ Med 1987;316:1429-35.

28 Scandinavian Simvastatin Survival Study Group. Randomised trial of cholesterol lowering in 4444 patients with coronary heart disease: the Scandinavian simvastatin survival study (4S). Lancet 1994;344:1383-9. 